\title{
Mídia e Juventudes: produzindo relações curriculares
}

\author{
Lisandra Veiga dos Santos* \\ Elisabete Maria Garbin**
}

\begin{abstract}
Resumo
É objetivo deste artigo perceber como estes discursos podem operar na constituição de um currículo paralelo na escola ou como se dão suas relações no cenário escolar, bem como na construção de identidades juvenis. Com base no campo dos Estudos Culturais, Estudos sobre Juventudes e algumas ferramentas foucaultianas, bem como de discussões sobre currículo de Silva, foram analisados 20 exemplares do Jornal Mundo Jovem dos anos de 2009 a 2010. As análises permitiram inferir que há um investimento na formação do jovem voltando-se para a ênfase religiosa. Bem como prescrições sobre o modo "verdadeiro" de ministra aulas e as formas mais corretas de fazê-lo. Com este artigo pode-se pensar como determinadas identidades juvenis são produzidas por discursos midiáticos e como podem ser associadas às representações produzidas e colocadas em circulação pelo Jornal Mundo Jovem.
\end{abstract}

Palavras - Chave: Juventudes - Mídia - Currículo - Práticas Pedagógicas

\section{Media and Youth: producing relations curriculum}

\begin{abstract}
Keywords: Youth - Media - Curriculum - Pedagogical Practices

[...] em outras palavras, eu diria que a mídia "caça" o jovem principalmente naquilo que o 'incrimina', tornando-o visivel no seu poder de juventude, sexo e beleza, resistência e agressividade, ao mesmo tem que na sua condição de miséria física e existencial. Assim, para além de objetivamente informarem sobre fatos, esses textos também afirmam e constroem um modo de diferentes vidas jovens existirem e serem expostas. (Fischer, 1996, p.249).
\end{abstract}

It is the aim of this article to see how these discourses can operate in the formation of a parallel curriculum in school or build their relationships in a school setting as well as in the construction of youth identities. From the field of Cultural Studies, Youth Studies and some tools Foucault, as well as discussions about curriculum Silva, were analyzed 20 copies of the Official World Youth the years 2009 to 2010. The analysis allows to infer that there is an investment in the education of youth turning to the religious emphasis. And prescriptions on how "true" minister of classes and more accurate ways of doing it. With this article can be thought of as certain juvenile identities are produced by media discourses and how they can be associated to the representations produced and put into circulation by the Official World Youth.

A epígrafe que inicia este artigo visa a introduzir a forma como irei abordar o tema da mídia, das juventudes e do currículo e de como pretendo tomar a mídia como produtora e produzida nessas relações. Esse incriminar, que Fischer cita, não é no sentido pejorativo, mas no sentido de que a mídia localiza as culturas juvenis para que possa "encaixotar, enquadrar, etiquetar, categorizar a juventude" (Garbin, 2000, p.10) e utilizá-la nos processos de adequação aos comportamentos socialmente aceitos, como se a produção de uma juventude 'normal' partisse de aspectos das juventudes denominadas pela sociedade como transgressoras para se instituir. Um exemplo da forma de 'pedagogização' das juventudes

Também é intento deste artigo discutir os discursos culturais que produzem os sujeitos e suas práticas escolares, atentando para o fato de que a mídia produz os sujeitos e suas relações com o entorno. Não quero afirmar nesse artigo que a mídia apenas produz; esse efeito de produção é uma via dupla, na qual a mídia produz e é produzida por discursos localizados em uma determinada época, por determinados sujeitos e suas relações de poder. É nessa relação de processo que pretendo desenvolver a linha de discussão desse artigo, não pensando em dominados ou 'alienados', mas sim em sujeitos que buscam um sentimento de pertença, um sentimento de segurança frente a um tempo - pósmodernidade- em que tudo se liquefaz, e se questiona e as estruturas fixas desmoronam.

Este artigo é um recorte de estudo maior pertencente a uma dissertação de mestrado, intitulada "Juventudes Contadas no Jornal Mundo Jovem: Modos de Pensar o sujeito jovem contemporâneo", e objetiva discutir, através dos exemplares de um jornal de grande circulação no

\footnotetext{
* Endereço eletrônico: lisandradaveiga@yahoo.com.br
}

** Endereço eletrônico: emgarbin@ @erra.com.br 
Brasil, a saber Jornal Mundo Jovem, as produções dos sujeitos jovens e das práticas pedagógicas ligadas a eles operando no currículos.

A metodologia constitui-se na análise de 20 exemplares dos anos de 2010 e 2011 através da leitura atenta e posterior debate em grupo de pesquisa. Os conceitos utilizados, a saber: discursos (Foucault, 2009), juventudes (Feixa, 2004; Garbin, 2002), currículo (Silva, 2007) foram um forma de "iluminar" as discussões dessas análises.

$\mathrm{Na}$ primeira seção, intitulada Inventário da mídia - percorrendo outras produções de sujeitos e espaços escolares, faço um breve levantamento de estudos que tomaram a mídia e suas relações - pedagogizantes ou não - e a juventude. $\mathrm{Na}$ segunda seção, Juventudes produzidas elou em processo de produção - dos discursos culturais que constituem os sujeitos jovens, analiso alguns discursos do jornal e suas produções de sujeitos contemporâneos jovens, bem como seus grupos culturais e o papel do pertencimento nesses grupos. Já na terceira seção, $O$ currículo - da constituição e transversalidade das diferenças, apresento algumas discussões acerca das concepções de currículo, bem como alguns trechos de análise dos discursos do Jornal Mundo Jovens que prescrevem modos e práticas pedagógicas. E na seção Da incompletude das discussõe, apresento as conclusões ainda que breves e parciais, tendo em vista que, se fossem analisadas sob outra ótica epistemológica, teriam outros encaminhamentos possíveis.

\section{Inventário da mídia - percorrendo outras produções de sujeitos e espaços escolares}

Apresento estudos já realizados sobre os temas mídia e juventude, os quais foram encontrados no Banco de Teses e Dissertações da CAPES e no repositório digital da Universidade Federal do Rio Grande do Sul (LUME/UFRGS). A saber: Neuman (1989) em sua dissertação de mestrado estudou a empresa que produz o Jornal Mundo Jovem, analisou como estava a situação da comunicação de massa no Brasil e no Rio Grande do Sul e a possibilidade dos indivíduos trilharem seus caminhos independentes desse meio. Fischer (1996) abordou em seu estudo a adolescência e a produção de sua subjetividade mediante a mídia. Garbin (2000) trabalhou com jovens e a sua relação com chats da internet, apontando os vários pertencimentos que estes jovens produzem e se identificam na internet. Schmidt (2006) lançou mão da Revista da MTV para explorar o termo "ter atitude" amplamente conhecida pelos jovens. Marques (2007) problematizou as culturas juvenis no Jornal Kzuka - um complemento do Jornal Zero Hora, do Rio Grande do Sul. Rossi (2007), a qual foi integrante do grupo de pesquisa do qual faço parte - investigou as culturas juvenis nas páginas do caderno Patrola, suplemento também do jornal Zero Hora. Souza (2008) analisou as formas pelas quais o Jornal Mundo Jovem comunica os paradigmas educacionais adotados no país desde a década de 1960, com o propósito de formar pessoas autônomas, criativas, críticas e solidárias, capazes de explorar o universo de suas construções intelectuais.

Em outros estudos, Gobbi (1999) analisou o jornalismo para teens e os espaços disponibilizados pelos jornais do Brasil para este público específico, também inventariou o perfil dos suplementos veiculados nas regiões Centrooeste, Nordeste, Norte, Sudeste e Sul, localizados na Folha de São Paulo, O Estado de São Paulo e $O$ Globo para compreender como se dá a participação dos leitores juvenis, bem como os objetivos da manutenção destas publicações pelas empresas jornalísticas nacionais. Gumes (2004) também trabalhou com o jornal Folha de São Paulo, mas analisando a identificação das culturas juvenis representadas no Folhateen, suplemento jovem e buscou também revelar como as identidades se configuram nos textos do jornal. Silva dos Santos (2005) analisou a imprensa de Fortaleza operando na construção das juventudes leitoras na década de 50. Nascimento (2008) direcionou seu olhar para a revista Veja e o jornal Folha de São Paulo dos anos de 1970 e 1980 e o modo como ela interfere nas produções da juventude e de suas estratégias. Pedrosa (2008) em seu estudo objetivou analisar o discurso da mídia, com destaque aos jornais impressos, sobre atos e fatos envolvendo jovens infratores, de forma mais específica na periferia de Natal. Oliveira (2009) analisou o discurso sobre a adolescente negra veiculado nas páginas da revista Atrevida. Stein (2011) focalizou seu trabalho na participação de jovens em um grupo religioso de orientação católica, o ONDA, pertencente a uma pastoral de paróquia da região do Vale do Rio dos Sinos. Com base na forma como vinte jovens participantes constroem o referente ONDA, em oficinas e entrevistas, a pesquisa investiga que representações os jovens constroem do trabalho realizado no grupo e quais as possíveis repercussões desse trabalho em relação à estruturação da vida em sociedade.

Tais trabalhos contribuem grandemente para o desenvolvimento deste artigo. Junto a eles agregamos discussões obtidas no grupo de pesquisa do qual faço parte, com essa combinação de concepções apresentadas, as quais produzem 
sujeitos jovens transitórios, com marcas culturais. Tais sujeitos se constituem de inúmeras formas e se utilizam de discursos midiáticos para comporem suas identidades.

Os discursos veiculados nesses estudos operam na lógica de outros artefatos culturais (revistas, internet, televisão, etc), mostrando juventudes, conscientes, disciplinadas, enfim, identidades juvenis. Este artigo analisa a mídia escrita de um jornal de uma determinada época, com discursos próprios, mas que de forma produz a juventude e seu modo se relacionar com as práticas pedagógicas contemporâneas. Segundo Foucault (2009), as práticas são resultados dos discursos e acabam de certa forma produzindo-os, nesse caso os discursos que produzem as juventudes também acabam por produzir práticas pedagógica, midiáticas, comportamentais específicas a conter ou desenvolver as culturas juvenis.

Necessita-se pensar que a mídia não é uma via de mão única e muito menos as pessoas são "coagidas" ou deixam-se levar pelos discursos, mas sim por que fora desses discursos nada faz sentido. Por anos a juventude foi vista como rebelde, soaria estranho comportamentos "adequados" ou jovens que não protestariam por nada. A barreira do adequado, do rebelde é a normalidade, ou seja, o que a sociedade espera do jovem como o seu "verdadeiro", o seu "normal" modo de se portar. Pode-se inclusive ampliar esse pensamento ao cotidiano da sala de aula, isto é, existem práticas que são legitimadas e tornadas verdadeiras, "normais" pelo currículo. As práticas pedagógicas também são produzidas pelos discursos contidos nos currículos, os quais expressam uma forma epistemológica de se conceber o sujeito e seus processos de aprendizagem.

Logo, pode-se conceber que a mídia tenha um papel de grande relevância na produção de discursos e que ela legitima modos de ser e de se conduzir o trabalho docente, seja em revistas ou programas destinados à exibir práticas pedagógicas, seja nos pareceres e diretrizes que veiculam, por meio de discursos inclusive, o modelo de sujeito que a escola Moderna busca formar.

Nessa concepção precisa-se sempre considerar o tempo histórico e seus processos nas construções dos discursos. Um exemplo dessa historicidade é pensarmos que o Jornal Mundo Jovem surgiu inicialmente no Seminário ${ }^{1}$ Maior de Viamão-RS, mas ainda não com esta denominação e com tal público. Em setembro de 1963 foi lançada a Revista "S.O.S. Vocações", (editada em português e espanhol) com o objetivo de atrair público para os seminários católicos. Servia basicamente de subsídio para as equipes vocacionais ${ }^{3}$. Em agosto de 1964, trocou sua nomenclatura para "Lançai as Redes", ainda com objetivos especificamente vocacionais, porém ampliando a abrangência. Destinava-se também aos trabalhos vocacionais nas paróquias e escolas. Em outubro-novembro de 1967, ainda no Seminário Maior de Viamão, o Jornal deu início a sua aproximação com público jovem, abordando e refletindo "suas inquietações, suas ansiedades e esperanças" (Jornal Mundo Jovem, 2011²). Foi neste período que adotou o atual nome de Jornal Mundo Jovem. Em janeiro de 1972 o Jornal Mundo Jovem passou do Seminário Maior de Viamão para a Pontifícia Universidade Católica do Rio Grande do Sul, sob a responsabilidade da Faculdade de Teologia, onde se mantém até hoje.

Vale ressaltar também nesse contexto que, em 1972, foi criado pela Igreja Católica, o primeiro Curso de Liderança Juvenil (CLJ) em Porto Alegre, organizado pela Igreja São Pedro ${ }^{4}$. Tais Cursos são pautados nos princípios do catolicismo, articulados aos discursos de liderança, autonomia, cidadania e responsabilização por decisões e escolhas. São culminados pelos chamados Retiros - espaços para reflexão e oração, organizados, em geral, locais afastados do centro urbano, para onde os jovens são levados e lá permanecem por alguns dias -, para reflexão, convidados a construir um mundo a parte, possível, 'melhor', dentro do cenário católico. Nesse cenário foi se constituindo o Jornal Mundo Jovem - um artefato que ensina modos de ser/estar jovem, professor, mulher, homem, cristão baseado nos preceitos da crença.

O jornal é composto por 21 seções, a saber, Espiritualidade, dos Leitores, Língua e Literatura, Projetos Pedagógicos, Educação, Ciências Naturais, Geografia, Ecologia, Sociologia, Arte e Cultura, Realidade brasileira, Filosofia, Ensino Religioso, Psicologia, Juventudes, Política e Cidadania, História, Vida saudável, Sexualidade, Pais e Filhos, Curtas e dicas, têm modos de endereçamentos distintos e formas de 'ensinamentos' sobre diferente, modos de pensar a docência. Separei para efeitos de visualização, as seções em três grandes vieses a partir das leituras das mesas, como por exemplo, as seções Espiritualidade, Filosofia, Ensino Religioso, Bíblia ${ }^{5}$, as quais tratam do aspecto religioso tendo contribuições de padres, irmãos, estudiosos de teologia que apontam para os benefícios de se fazer parte de um grupo de jovens da Igreja, as reflexões proporcionadas pela campanha da fraternidade, passagens bíblicas, valores éticos segundo a religião católica. Já nas 
seções: Projetos Pedagógicos, Educação, Ciências Naturais, História, Geografia, Ecologia, Língua e Literatura, podem se observar modos de endereçamento a professores, com discussões e materiais de apoio ao pé da página, como perguntas sugeridas para debate em grupo. Um vocabulário mais complexo e com professores de cada área que dão contribuições de artigos àquelas seções.

Para analisar este artefato cultural, do qual constitui-se o jornal Mundo Jovem, lancei mão do campo dos Estudos Culturais para analisar os discursos do referido jornal. Os Estudos Culturais propõem um conjunto de abordagens, problematizações e reflexões situadas na confluência de vários campos já estabelecidos, buscando inspiração em diferentes conceitos, rompendo com lógicas cristalizadas. Esses estudos têm início nas análises das sociedades industriais modernas (Nelson; Treichler; Grossberg, 2009), de suas práticas e de seus sujeitos. Com o passar do tempo e das rupturas político-históricas, os Estudos Culturais tiveram suas direções ampliadas para outras discussões, tais como: a educação, a tecnologia, gênero, etnia, juventudes, sociologia, etc.

No entanto, sempre mantiveram seu objeto de observação: a cultura. Inicialmente a cultura foi pensada por três modos conforme Williams citado por Costa

No primeiro, [modo] diz ele, há o "ideal" - a cultura como tomada como um processo de aperfeiçoamento, direção a valores universais e absolutos. $O$ segundo se refere a cultura como "o documentário", o conjunto da produção, do trabalho intelectual e criativo. Em terceiro lugar está uma definição social de cultura - a cultura como descrição de um modo de vida. É esta última definição que inspirou e orientou os Estudos Culturais. (WILLIAMS apud COSTA,2004, p.24).

Este primeiro conceito de cultura cunhado por Williams (1965) foi se transformando ao longo de tempo, como outros autores, outras áreas de estudo envolvidas e foi inevitável o deslocamento para uma outra forma de pensar a cultura. Para os Estudos Culturais, tal deslocamento é algo importante pelo próprio campo considerar os processos de ressignificação ou até mesmo o borramento de determinadas metanarrativas. Podemos conceber a cultura e suas inúmeras relações com outros campos como formas de articulação desses estudos, como sendo a possibilidade de integração e de modos de concepção diferenciados da vida social, sem necessariamente restringi-las a classe social. A educação vista sob a perspectiva dos Estudos Culturais, por exemplo, apontam para uma parceria produtiva para discussão,

$\dot{E}$ possível dizer que os estudos
conduzidos na direção apontada tem
facilitado a não circunscrição da
pesquisa em educação, bem como das
ações educativas, às tradições tomadas
como prevalentes às compreensões
definidas como hegemônicas, às histórias
de progressos cumulativos e as análises
interpretativas que buscam o sentido
oculto das coisas, ou que reduzem a
crítica e a denúncia" (Wortmann, 2005,
p. 174).

A autora aponta a elasticidade que os Estudos Culturais proporcionam ao utilizá-los em pesquisas no campo da educação, o quanto tais estudos podem contribuir para pensar sobre escola, aluno, relação professor-aluno, etc. Discutir a educação do ponto de vista dos Estudos Culturais, além de incitar outras formas de olhar, não restringe o sujeito ou suas práticas a determinismos sociais. Hall (2003) ainda destaca que os Estudos Culturais abarcam discursos com múltiplos saberes veiculados através práticas sociais cotidianas e que o campo de estudo procura não organizar $\mathrm{o}$ conhecimento em disciplinas, mas sim misturá-los, borrar suas fronteiras. Esse 'borramento' se daria de maneira que se possa entender, de múltiplos modos, questões que muitas vezes ficariam na esteira de discussões localizadas e perderiam outras possibilidades de análise se não inscritas no campo dos Estudos Culturais. Tal campo tem ressignificado e tornado dinâmicas as discussões acerca de identidade, discurso e representação (Costa, Silveira, Sommer, 2003).

Nas seções Projetos Pedagógicos, Educação e Psicologia explicitam-se tais discursos acerca de como concebemos a cultura do bom aluno, como podemos observar no excerto a seguir, da edição de Março de 2009

Na escola foi possivel perceber que houve melhora no desempenho dos alunos, bem como uma maior integração entre eles. Também foi possível identificar que a experiência do diálogo entre as disiciplinas [...] contribui para o aumento da responsabilidade e do interesse dos alunos pelas aulas, assim como sua 
atuação como cidadãos, para além do espaço escolar. (Neves, 2009, p.21).

A melhora à qual o excerto se refere tem a ver com o "aumento da responsabilidade e do interesse dos alunos pelas aulas (Neves, 2009)", ou seja, o modo de ser aluno que contribuiria com o bom andamento das aulas seria o responsável e interessado. Não se questiona se tal excerto é adequado ou não, nem se emitem opiniões acerca da publicação, mas sim problematizam-se os tipos de discursos que percorrem, inclusive o currículo, as práticas pedagógicas. $\mathrm{O}$ sujeito aluno precisa ser incentivado a ter determinados comportamentos que auxiliariam na melhora da escola.

No excerto da seção Educação, da edição de Maio de 2009, em uma reportagem acerca da escrita, pode-se observar algumas prescrições e modos de ser que seriam adequados a boa prática da escrita, "O texto como um espaço em que o aluno possa ser leitor e também autor, utilizando suas experiências de vida, seu conhecimento prévio como fonte de produção." (Cargnin, 2009, p.5) Também visualizamos as mesmas prescrições no excerto retirado da Seção Educação, da edição de Abril de 2010, que "exige dos estudantes uma atitude investigativa, na qual o confronto com o que se sabe e o que deseja saber resulte no questionamento da realidade. (Jucá, 2010, p.18)". O referido trecho faz parte de uma reportagem que trata da importância de uma postura de pesquisador cientifico. Ao longo da reportagem a autora busca atentar para a importância de se estimular a pesquisa desde cedo nas escolas. Inclusive, a pesquisa que também é um elemento que faz parte do currículo, é produzida como uma forma de se "aproximar o mercado e trabalho da formação como seu produto (Jucá, 2010, p. 18)".

Em se tratando de trabalho por projetos, pode-se observar que o comportamento sugerido ao aluno, retirado da Seção Projeto Pedagógico, da edição de Julho de 2009, é o de desenvolver "competências e habilidades como observação, trabalho em equipe, criatividade, organização, registro de situações de aprendizagens. [...] (Pereira, 2009, p.19)". Tais habilidades estão ligadas a uma concepção de sujeito contemporâneo, o qual deve-se investir no capital cognitivo (Foucault, 2009) do sujeito como forma de desenvolvimento da sociedade do conhecimento, a qual se desenha com as tendências atuais na educação. A escola na percepção dessa sociedade não mais atua como formadora única, mas estimula o sujeito a se autogerir na perspectiva do trabalho em equipe e por projetos. Existem relatos de algumas escolas públicas trabalhando nessa perspectiva.

Também, no sentido de produzir discursos acerca do currículo, observou-se modos de se conceber as práticas do cotidiano como sendo encaminhadas e prescritas, como no excerto retirado da seção Educação, da edição de 2009

\begin{abstract}
$O$ conselho deve ser um espaço de decisão coletiva. Desta forma permite enfrentar o desafio de construir um novo projeto para escola. Tem como um dos objetivos refletir sobre a aprendizagem, proporcionando um espaço de reflexão coletiva sobre o trabalho pedagógico. (Edição Outubro, p.12).
\end{abstract}

Segundo, Steinberg (1997), a mídia produz no sujeito e em suas relações uma pedagogia cultural, na qual ensina modos de ser que são considerados aceitáveis na sociedade em que vive. Corroborando tal ideia, Foucault (2009) nos diz que a produção desse sujeito e do modo de ser é datada de cada época, a qual possui um conjunto de discursos específicos, o que o autor chama de episteme. À cada momento história as relações e os sujeitos são produzidos e produzem relações de poder através das epistemes que regem a sociedade. No excerto anterior, o jornal coloca as funcionalidades e objetivos de um Conselho de Classe, uma prática típica na escola moderna, sugerindo ao leitor outro modo de condução e concepção do mesmo.

\section{Juventudes produzidas e/ou em processo de produção - dos discursos culturais que constituem os sujeitos jovens}

\begin{abstract}
Dentro de nós há identidades contraditórias, empurrando em diferentes direções, de tal modo que nossas identificações estão sendo continuadamente deslocadas. Se sentimos que temos uma identidade unificada desde o nascimento é porque construímos uma cômoda estória sobre nós mesmos ou uma confortadora ' narrativa do eu'. (Hall citando Hall, 2006, p.13).
\end{abstract}

Ao analisar o Jornal Mundo Jovem a partir do campo dos Estudos Culturais, tornou-se possível depreendê-lo como um artefato que, por meio da linguagem, dos discursos, produz compreensões sobre ser/estar jovem. Considerando as múltiplas possibilidades que se produzem na contemporaneidade, perpassando a constituição de identidades efêmeras, fluidas e, 
por vezes, contraditórias como afirma Hall (2006), analisei nesta seção os modos, os discursos nos quais o jornal procura produzir as identidades das juventudes contemporâneas. Por se tratar de um jornal que possui em sua trajetória as fortes marcas da própria história do catolicismo, passo também a 'tensionar' em que medida também não estaria produzindo identidades católicas.

Partindo da compreensão de que as identidades podem ser múltiplas e cambiantes, essas convocam o sujeito simultaneamente a diversos pertencimentos. Nosso tempo líquido faz com que as experiências que temos sejam mais valorizadas quando em grupo, o grupo seria o porto seguro, a garantia que foi levada com a Modernidade.

O jovem pode ser católico, no entanto gostar de roupas de marca, de rock n' roll, frequentar bate-papos virtuais, andar de skate, ou vir hip-hop sem, no entanto, romper com sua identidade católica. Esta seção dará visibilidade a alguns discursos acerca das juventudes, dentre tantos que habitam a mídia e o próprio jovem de modo simultâneo.

Conforme Ellsworth (2001, p.20) sugere, o filme, com seus modos de endereçamento, espera que o espectador aja "como se ele fosse aquele alguém que o filme quer que ele seja, que o filme pensa que ele é, ou ambas as coisas.", essa é a maneira de funcionamento dos modos de endereçamento. Descrever detalhadamente um sentimento, atribuir uma característica que chame a atenção do espectador. No caso do jornal, atribui-se a juventude um caráter de dinâmica, "que sabe lidar com novos meios eletrônicos", que devemos aprender com essa juventude. No entanto, mais do que isso o artigo que destaco a seguir chama a importância de se aprender com as gerações, tendo em vista que parece endereçado a outra geração que não a da juventude. É esse endereçamento que produz a identidade, ou os processos de identificação (Hall, 2006), pelos quais as juventudes se reconhecem no jornal e pelos quais os professores e a escola também se reconhecem como sujeitos da ação e da reflexão.

$O$ sentimento de que temos uma identidade apenas e que vivemos eternamente sob os parâmetros dela é uma visão comumente confundida com a ética e a moral, as quais pautam nossas ações desde que a aprendemos para o resto da vida. Em parte essa ética é formada pela religião e pelos discursos sobre o que é certo/errado de se agir. No jornal encontramos os modos de endereçamento aos jovens para que estes pautem suas ações pela religião, que implica a moral e ética, mas que é construída sob maneira através dos processos de identificação desses jovens com o catolicismo sob o viés dos discursos presentes no jornal, como nos mostra os excertos a seguir

Para captar toda a riqueza de vida presente na Bíblia, é importante de um lado olhá-la como produto literário que pode e deve ser analisado à luz da história e da crítica textual. Essa leitura responde às nossas buscas no entendimento da palavra, pois queremos compreender o seu sentido. Isso é bom, mas não suficiente. É que a Bíblia não é um conjunto de conhecimentos teóricos como as demais ciências. Não é um livro de biologia ou de astronomia, de física ou de história, mas é um livro de teologia, um livro de fé, escrito por pessoas de fé para comunidades também de fé. (Uma palavra para a nossa vida, Edição de Fevereiro, p.15, 2009).

A palavra de Deus deve ser o nosso alimento cada dia e nela precisamos buscar o sustento para nossa vida. (Bíblia (ainda não) é um livro ecumênico, Edição de Setembro, p.9, 2010).

Mas atenção!Ao lado de toda a sede de poder, fama e dinheiro existe uma necessidade ou exclusão correspondentes. (Consumismo quem é vencedor?, Edição de Março,p.16, 2009).

Os excertos apresentados procuram ressignificar as identidades juvenis, as quais são produzidas através dos modos de endereçamento sugeridos nos excertos. Não basta ser católico, tem que seguir uma série de práticas, de modos de se conduzir para pertencer ao grupo. Podemos transpor tais conclusões às práticas pedagógicas, as quais buscam trabalhar com o grupo ao sujeito, homogeneizar ao ver a heterogeneidade do cotidiano escolar. Esses modos de endereçamento também estão presentes no currículo, tendo em vista que eles são endereçados a certas classes sociais e modos de se produzir sujeitos na escola Moderna.

Essas verdades, ao endereçar-se ao público juvenil, o Jornal produz como estratégia de interpelação a aproximação de seus temas a assuntos que a equipe editorial julga presente neste "Mundo Jovem". Cito os seguintes exemplos pela sua recorrência

Vale ressaltar o uso do graffiti em escolas $e$ instituições como forma de socialização 
$e$ expressão cultural, bem como a abertura de espaços cada vez mais significativos em galerias de artes de arte e museus. (Graffiti: outros olhares para a escrita das ruas, Edição de Maio, p.2, 2009).

Também seria legal convidar alguns grafiteiros para um debate na escola a fim de conhecer essa expressão da cultura juvenil. (Graffiti: outros olhares para a escrita das ruas, Edição de Maio, p.2,2009).

Conhecer para entender (Funk: embalando as comunidades e a escola, Edição de Setembro, p.5, 2009).

É possível aproveitar as culturas juvenis para enriquecer a relação entre professor e aluno?

Ela (a escola) precisa compreender como se dá essa escrita e utilizá-la a favor do ensino de língua principalmente. (A (nova) escrita digital, Edição de Março, p.22, 2010).

Portanto, é notório o movimento do Jornal em debater temas articulados a culturas juvenis, tanto pela sua recorrência na análise do artefato como pela sua referência conforme a narrativa da equipe editorial

As juventudes que são retratadas no Jornal Mundo Jovem não são apenas católicas ou de orientação cristã; são exibidas nas páginas do Jornal as juventudes rurais, as juventudes em condições economicamente desfavoráveis, bem como suas culturas, como podemos observar nos títulos do artigos a seguir: Graffiti: outros olhares para a escrita das ruas; Corpos jovens: espaços de comunicação de si; Sites de Relacionamento: uma mania mundial, Vida Urbana e Vida Rural desafios ao jovem agricultor; Formação Integral do Jovem; Funk embalando as comunidades e a escola; Mitos e Preconceitos em torno da homossexualidade; Hip-Hop: um grito por liberdade.

As juventudes descritas no jornal são produzidas a partir de seus estilos (Feixa, 2004) musicais, artísticos, etc, assim como modos de ser. Jovens que fogem ao padrão de comportamento também são tema das publicações no sentido de servirem de exemplificação de modos de ser adequados ou não. Se pensarmos nessa lógica, a mídia também produz o aluno indisciplinado, mas não modo passivo e unilateral, e sim inserido no contexto da escola
(Xavier,2003), onde se espera desse sujeito determinados comportamentos, amplamente tratados na mídia. Para tanto, quando se fogem desses modos de ser, logo produz-se o sujeito indisciplinado, aquele cujo modo de ser extrapola a normalidade e "atrapalha" o andamento da aula. O jornal trabalha numa perspectiva combativista de comportamentos que vem de encontro ao que a escola preconiza, tais como bullying, violência, consumismo, relações pessoais e relações nas redes sociais.

Sabe-se que o modo como a mídia conduz suas relações tem muito a ver com o que se espera do sujeito. Nesse sentido o sujeito aluno é produzido por um currículo Moderno que tem no modo contemporâneo o referencial de comportamento do alunado. Aceita-se que o sujeito aluno jovem tenha muitas distrações e mesmo assim aprenda, não aceita-se é o seu não aprendizado, sua dificuldade. Logo, problematizase na mídia e no dia-a-dia mais a incapacidade e dificuldade, que os avanços e do que tal sujeito é capaz de aprender.

\section{O currículo - da constituição e transversalidade das diferenças}

O currículo tem significados que vão muito além daqueles os quais as teorias tradicionais nos confinaram. O currículo é lugar, espaço, território. O currículo é relação de poder. O currículo é trajetória, viagem, percurso. $O$ currículo é autobiografia, nossa vida, curriculum vitae: no currículo se forja nossa identidade. O currículo é texto, discurso, documento. $O$ currículo é documento de identidade. (Silva, 2007, p.150).

A partir do excerto do autor Tomaz Tadeu da Silva podemos refletir acerca do papel do currículo na escola e como este produz e é produzido através das diferenças veiculadas pela mídia. A mídia, longe de ser vilã, atua, conforme referendei anteriormente, na constituição dos sujeitos e também na constituição das práticas vividas por esses sujeitos em seu cotidiano. Além do Ministério da Educação que produz legislações, currículos e diretrizes, a mídia impressa e televisiva também expõe modelos do que uma educação "precisa", até propõe em alguns casos "respostas à educação" revistas especializadas no assunto propõem conteúdos, sequências didáticas e modos de se abordar temas do currículo. Esse currículo é a vida do aluno, do professor, da escola, conforme pudemos observar na epígrafe. Seria a vida da 
escola também produzida? Produzida sob quais perspectivas na mídia? Faz-se importante pensar acerca dessa produção.

$\mathrm{Se}$ os sujeitos e suas relações são produzidos através dos discursos midiáticos também, e tomo como assertivo o enunciado que os sujeitos também produzem os discursos, podemos pensar no Silva $(2007$, p.148) apresenta "através das relações sociais de currículo, as diferentes classe aprendem quais são seus respectivos papéis nas relações sociais mais amplas.". Longe de empreendermos uma discussão materialista ou até mesmo na teoria da ideologia proposta por Althusser, o currículo tem esse papel de constituir a subjetividade dos sujeitos e os sujeitos a criarem situações de resistências $^{7}$ ao currículo num jogo dinâmico de poder. O que se deve aprender e como se deve estão intimamente ligados às relações culturais e às funções que determinado público irá tomar parte na sociedade.

As relações culturais implicam o currículo sob uma perspectiva de discussão do sujeito enquanto partícipe de uma determinada época, de um determinado cenário cultural e trabalhar com essas questões parecem mais fundamentais à mídia que as pessoas responsáveis pela construção do currículo. É nesse encontro de culturas e conhecimentos formais que Silva (2007, p.136) propõe pensar no "[...] conhecimento como um objeto cultural, uma concepção do currículo inspirada nos Estudos Culturais equipararia, de certa forma, o conhecimento propriamente escolar com, por exemplo, o conhecimento explicíta ou implicitamente transmitido através de anúncio publicitário.", ou seja, a possível trégua ou vivência simultânea da mídia, das culturas e dos conhecimentos escolares poderia ser uma das possibilidades de se trabalhar a constituição do sujeito e transformar sua condição, de sujeito passivo receptor, para ativo e produtor.

Propõe-se pensar na relação dialógica que o cenário contemporâneo tem na escola, ignorar o que os sujeitos fazem fora da sala de aula é ignorar sua constituição cultural. As juventudes culturais que se formam fora da escola trazem seus pertencimentos para dentro dela, continuam vivenciando-os, ainda que separadamente do que é considerado conhecimento escolar formal. A maioria dos docentes propagam a ideia de que as juventudes contemporâneas são diferentes das que eles viveram, mas o discurso para por aí. Ao invés de se pensar nessas juventudes enquanto comparativo, deveríamos mesclar os seus conhecimentos culturais ao currículo, torná-lo flexível dentro de um sistema Moderno e rígido. Desafiar os jovens a compreenderem o tempo em que vivem pelas experiências que têm, dentro e fora da escola. Desacreditar em enunciados como "essa juventude está perdida!", “é isso que serão os adultos de amanhã?" e ajustar o foco ao dinamismo, ao convívio pacífico com as diferenças e a possibilidade infinita de adaptação.

Pensando nesse modo de conceber o currículo, analisei as 21 seções do jornal e por motivos de recorrência, escolhi dois temas de duas seções: Educação e Projetos Pedagógicos, pois notei regularidades nessas duas grandes seções, as quais permeiam em grande parte o Jornal modos de ser professor e modos de se conduzir o trabalho docente. Não podemos deixar de conceber o currículo sem as relações de docência que também estão implicados neles e também são produzidos e produtores

Na seção Projetos Pedagógicos dos anos de 2009 e 2010, podemos observar o seu endereçamento aos docentes, principalmente a realização do trabalho docente. São artigos que sugerem práticas pedagógicas ao professor de acordo com assunto do mês da capa. É possível notar algumas correntes de pensamento pedagógico sobre educação, como no excerto a seguir do artigo Ensinar é aprender

Os estudantes estão abastecidos por uma
carga de informações cuja capacidade de
assimilação nem comporta. O ser humano
tem potência de semideus, com emoções
de mortal. O avanço da era espacial em
que vive se tornou o ser humano
angustiado pela consciência de sua
fragilidade para absorver e superar os
desafios a sua volta. (Edição de
Fevereiro, p.6, 2009).

Excetuando o caráter poético do trecho anterior, podemos inferir uma concepção construtivista do aprender, que vê nos processos de assimilação um de seus principais elementos de desenvolvimento. No entanto, o excerto destaca também o sentimento que possivelmente habita os seres da pós-modernidade, a angústia pela "consciência de sua fragilidade para absorver e superar os desafios a sua volta." (p.6, Fevereiro, 2009), mas que o excerto traz como uma característica do desenvolvimento do ser humano, numa provável referência a sua evolução.

Há também presentes nos artigos do Jornal prescrições sobre como se deve empreender o projeto, o papel do professor e da escola. Poderíamos inferir que tais indicações para o desenvolvimento do trabalho docente seriam uma forma de conduzir a conduta desses docentes; seria uma forma de explicitar os modos certos, 
verdadeiros de ser professor. O excerto a seguir, retirado do artigo Educar para a cidadania

Educar para a cidadania é aspirar uma escola que prepare pessoas não apenas para o trabalho, mas para participar no mundo globalizado de forma crítica, reflexiva e emancipatória. (Edição de Abril,p.15, 2009).

É interessante observar que conceitos complexos como participação crítica, reflexiva e emancipatória aparecem como de comum acordo sobre seus significados, e que isso levante a questão sobre que referenciais o Jornal ou a escritora do texto concebe a crítica. Por exemplo, numa perspectiva foucaultiana, a crítica vai além de se levantar os pontos negativos, interpretar possíveis relações de causa e conseqüência, mas atentar para que jogos estratégicos essa crítica põe em circulação e quais verdades ela movimenta.

Também podemos observar que a estrutura da seção aparece, quase sempre, da mesma forma, apresentando um quadro abaixo do texto principal, no qual há a descrição do projeto, intitulado Acontecendo na prática ou ainda Passo a passo, com base na fala de outros docentes que já o realizaram e obtiveram sucesso. Já em uma outra coluna dentro do texto há a subseção Avaliação e Objetivos, que prescreve de que forma pode se dar a avaliação do projeto e dos sujeitos envolvidos nele. Também há uma estrutura à esquerda da página denominada Ficha Técnica, com dados dos objetivos do projeto, tais como turmas envolvidas, equipe envolvida, duração, recursos materiais, avaliação e premiação.

Podemos inferir também diferentes modos de se conceber o mundo contemporâneo que acabam por permear as escritas dos artigos, por exemplo as oposições de "moderno e antigo", ou das práticas que tínhamos com as que temos agora, como se nossa linha do tempo fosse de fato uma linha linear e que nos levasse à evolução, como no trecho a seguir extraído do artigo Atividade Física e Qualidade de Vida

Convém lembrar que a vida moderna tem vantagens e desvantagens que podem levar o ser humano a se tornar inativo. Automóvel, computador, telefone, televisor e CD são excelentes instrumentos para locomoção, comunicação, educação e lazer. No entanto, toda essa tecnologia contribui para o atual estilo de vida: sedentarismo, alimentação inadequada e hábitos nocivos. Por outro lado a missão das pessoas é manter-se saudável. (Edição de Agosto, p.7, 2009).

O provável objetivo do artigo é incentivar a prática de esportes e dar ênfase aos projetos ligados a ele; no entanto, para atender ao publico leitor, que além de professores também é composto por jovens, ou seja, aproxima-se esse artigo com o que a contemporaneidade oferece para dar maior valor a prática de esportes, isto é, com uma vida "moderna" sedentária, precisamos realizar esportes.

Os artigos que estão presentes nessa seção, ao contrário da seção Projetos Pedagógicos, são escritos por especialistas em educação, psicólogos. e não por professores com seus relatos de experiência; logo, seu modo de endereçamento é diferente no que tange à legitimidade do discurso, pois são especialistas que conferem o código de verdade necessário ao texto.

As temáticas abordadas são múltiplas, mas na maioria das vezes apresentando posicionamentos firmes e delineados, como podemos observar no excerto a seguir, retirado do artigo Aprendizagem para Todos

Discutir a educação de alunos com
necessidades especiais implica resgatar o
sentido da educação especial, ainda que
isso possa desagradar aos que se colocam
à frente das discussões sobre educação
inclusiva. Diante de necessidades
educacionais especiais, a educação
escolar deve promover situações de
ensino e aprendizagem diferentes das
organizadas para a maioria dos
educandos. (Edição de Março,p.15,
2009).

$\mathrm{O}$ autor defende que a inclusão deve ser pensada de forma mais cuidadosa, mas ainda sob a égide de incluir a todas as necessidades. Não é objetivo deste artigo discutir este posicionamento, nem fazer juízo de valor acerca dos assuntos tratados pelo Jornal, mas sim propor outros olhares a leitura desse artefato cultural, que possibilita pedagogizar as discussões acerca da educação e do trabalho docente. Os artefatos não possuem poder de influência sobre seus leitores, mas sim de sedução aos processos de subjetivação e encontram na prescrição a sua sustentabilidade. Ao oferecer modos de ser docente, de se conceber a educação, essas verdades subsidiam técnicas de si, atuam diretamente no governo de si, como podemos visualizar no trecho a seguir extraído do 
artigo Educação Infantil, muito mais do que cuidar

Com o passar do tempo, a responsabilidade do educador é de desenvolver uma educação que promova $o$ amadurecimento da autonomia, direcionando suas ações, sem esquecer-se dos limites essenciais do ambiente e o que ela tem internamente, como afetividade, conhecimento, sociabilidade entre outros fatores. (Edição de Maio, p.6, 2009).

Essas concepções de educação nos dão pistas de como o trabalho docente está implicado no discurso do campo pedagógico. Apesar de ser um artigo voltado à Educação Infantil, podemos depreender daí toda uma rede discursiva que visa a produzir verdades disponíveis aos sujeitos que empreendem a carreira docente. Podemos observar nos excertos que se seguem a força desses discursos prescritivos nas concepções de educação vigentes na nossa sociedade

Educar, portanto, significa propiciar situações de cuidado, brincadeiras $e$ aprendizagem, orientadas de forma integrada visando ao desenvolvimento das capacidades de relação com o outro, atitudes de aceitação, respeito, confiança $e$ também possibilitar o acesso ao conhecimento da realidade social $e$ cultural. (Edição de Maio, p.6, 2009).

Educar envolve, ainda, o desenvolvimento das capacidades de conhecimento e das potencialidades corporais, afetivas, emocionais, estéticas e éticas. (Edição de Maio, p.6, 2009).

A Educação deve ser um instrumento que possibilite a emancipação social do ser humano, capacitando para a sua vida para a vivência coletiva e a conquista da dignidade. (Edição de Maio, p.6, 2009).

Podemos inferir, ainda que parcialmente, que as prescrições não são ideológicas ou coercitivas, mas agem de tal modo que, fora dessa rede discursiva, a educação, o trabalho docente não tem sentido. Não é uma rede que age silenciosamente, mas que se tornar parte do que é considerado verdadeiro no trabalho docente.

\section{Da incompletude das discussões}

Neste artigo busquei trabalhar com a noção de currículo aliada a discursos do Jornal Mundo Jovem, debatendo e problematizando a produção da mídia de sujeitos e das relações desses com o currículo. A cultura, as juventudes, a mídia agem de forma cíclica no currículo evidenciando assim um sujeito totalmente contraditório e 'silenciado' em sua cultura.

No entanto, se tomarmos o Jornal Mundo Jovem como artefato cultural, também pode significar tratá-lo como uma prática que constitui discursos sociais próprios da cultura referida, como exemplificam Costa; Silveira \& Sommer

um noticiário de televisão, as imagens, os gráficos, etc. de um livro didático ou as músicas de um grupo de rock, por exemplo, não são apenas manifestações culturais. Eles são artefatos produtivos, são práticas de representação, inventam sentidos que circulam e operam nas arenas culturais onde o significado é negociado $e$ as hierarquias são estabelecidas. (Costa; Silveira \& Sommer, 2003, p.38).

Os artefatos são os objetos concretos, são as práticas culturais que acabam por veicular 'ensinamentos' a sociedade, tais como o Jornal Mundo Jovem, que busca endereçar à comunidade jovem modos de pensar a sua juventude, modos de propor pautas para o debate da condição juvenil. De um modo geral, este estudo concebe o Jornal, que será material de análise, como um artefato, o qual Bujes (2000).

Refere-se a qualquer objeto que possui um conjunto de significados construídos sobre si. 'Produtos' de culturas que dão visibilidade a determinadas representações sobre as coisas. Tais representações atuam nos processos de significação que produzem sentidos na vida da cada sujeito. Estes significados só podem ser construídos através da linguagem. É no âmbito das práticas discursivas que se dão tais construções. Ao mesmo tempo em que um artefato cultural se caracteriza por ter sobre si determinados significados, ele é também um produtor de significados. Muitos deles criam realidades e verdades sobre as coisas, as quais são postas em circulação para serem consumidos. (Bujes, 2000, p. 205-228). 
Du Gay (1997) assinala que "para estudar os artefatos culturais precisamos não apenas explorar como são representados, que identidades sociais estão a eles associadas, mas também como são produzidos, consumidos e que mecanismos regulam sua distribuição e uso". Os artefatos são resultados de uma produção cultural específica datada historicamente e constituída por sujeitos sociais. Estudando artefatos culturais também podemos depreender inúmeros modos de pensar e de ser sujeito. Du Gay et. all,(1997), estudando o walkman, assim argumentam,

[...] nós não estamos apenas tratando do modo no qual um artefato cultural é representado (como uma coisa na propaganda e nas fotografias), mas também tratando como os processos que tem produzido esse artefato tem sido representado. Nós precisamos pensar sobre como os vários processos de produção são entendidos e recebem significados ao serem rotulados $e$ categorizados de vários modos (inovador japonês, trabalho em equipe etc..). (Du Gay et all, 1997, p.8).

O presente artigo utilizou-se desse artefato cultural para problematizar os discursos que veiculam por ela sobre juventudes, currículo e práticas pedagógicas. Após as análises já apresentadas, pode-se inferir, ainda que parcialmente, que o Jornal Mundo Jovem, o qual possui artigos localizados numa racionalidade contemporânea, prescrevem modos de ser aluno, jovem, docente e de conduzir seus trabalhos por finalidades, como a de promover a autonomia do aluno, de desenvolver valores éticos cristãos aliados as suas metodologias e de estar ligado a temas que necessariamente passem pela metodologia de projetos. Podemos considerar que os discursos sugerem o consumo de determinadas culturas, que adotem seus modos de ser, que se constituam em determinadas práticas docentes. Outra forma de pensar os pertencimentos que o jornal oferece aos professores é observar que, nos artigos que seguem, ele tenta exibir a representação de juventude que está ou não presente na sala de aula. Ao interpelarmos esses discursos presentes no Jornal Mundo Jovem a fim de delinear as identidades e os trabalhos docentes que aparecem nele, podemos observar um movimento que o Jornal realiza, o de buscar conhecer a juventude e dar informações sobre ela aos professores que, em sala de aula, procuram governá-los.
O currículo não é mais centro de poder, mas sim distribuição de práticas culturais, norteamento das práticas pedagógicas. A mídia teria seu espaço garantido na escola mediante a construção de sujeitos culturais, pergunto-me.

\section{Referências}

BUJES, Maria Isabel. Criança e brinquedo: feitos uma para o outro. In: Estudos Culturais em Educação: mídia, arquitetura, brinquedo, biologia, literatura, cinema... Porto Alegre: Ed Universidade/UFRGS, 2000, p.205228.

CAMOZZATO, Viviane Castro. Habitantes da cibercultura: corpos 'gordos' nos contemporâneos modos de produzir a si e aos 'outros'. Dissertação de Mestrado. Programa de Pós-Graduação em Educação. Universidade Federal do Rio Grande do Sul, 2007.

CANDIOTTO, César. Foucault e a Crítica da verdade. Belo Horizonte: Autêntica Editora. Curtiba: Champagnat,2010.

CNBB - Conferência Nacional dos Bispos do Brasil. Marco Referencial da Pastoral da Juventude do Brasil. Cadernos de estudo da CNBB - no 76. São Paulo: Paulus, 1998.

COSTA, Marisa Cristina Vorraber. Estudos Culturais - para além das fronteiras disciplinares. In: . Estudos Culturais em Educação: mídia, arquitetura, brinquedo, biologia, literatura, cinema... Porto Alegre: Ed Universidade/UFRGS, 2000, p.13-36.

COSTA, Marisa Vorraber; SILVEIRA, Rosa Hessel; SOMMER, Luis Henrique. Estudos Culturais, educação e pedagogia. Revista Brasileira de Educação. Rio de Janeiro: Editora: Autores Associados. Maio/Jun/Jul/Ago, 2003, $\mathrm{n}^{\circ} 23, \mathrm{p} .36-61$.

DU GAY, ET ALL. Doing Cultural Estudies. The Story of the Sony Walkman. Londres: Sage, 1997.

ELLSWORTH, Elizabeth. Modos de endereçamento: uma coisa de cinema; uma coisa de educação também. In: Silva, Tomaz Tadeu da. Nunca fomos humanos - nos rastros do sujeito. Tradução de Tomaz Tadeu da Silva. Belo Horizonte: Autêntica, 2001, p.7-76. 
FABRÍS, Eli Terezinha. Em cartaz: o cinema brasileiro produzindo sentidos sobre escola e trabalho docente. Tese (doutorado) - Universidade Federal do Rio Grande do Sul. Faculdade de Educação. Programa de Pós-Graduação em Educação, Porto Alegre, 2005.

FERREIRA, Tais. Teatro infantil, crianças espectadoras, escola: um estudo acerca de experiências e mediações em processos de recepção. Dissertação de Mestrado. Programa de Pós-Graduação em Educação. Universidade Federal do Rio Grande do Sul, 2005.

FEIXA, Carles. Jovens na América Latina. São Paulo: Escrituras, 2004. 327 p.

FISCHER, Rosa Maria Bueno. Adolescência em discurso: mídia e produção de subjetividade. Tese (doutorado) - Universidade Federal do Rio Grande do Sul. Faculdade de Educação. Programa de PósGraduação em Educação, Porto Alegre, 1996.

FOUCAULT, Michel. A Arqueologia do saber. 7. ed. Rio de Janeiro: Forense Universitária, 2009.

GARBIN, Elisabete Maria. Cultur@s juvenis, identid@des e Internet: questões atuais... Revista Brasileira de Educação. Rio de Janeiro: Editora: Autores Associados. Maio/Jun/Jul/Ago, 2003, n²3, p.119-135.

GARBIN, Elisabete Maria. www.identidadesmusicaisjuvenis.com.br : um estudo de chats sobre música da Internet. Tese de Doutorado. Programa de Pós-Graduação em Educação. Universidade Federal do Rio Grande do Sul, 2000.

GOBBI, Maria Cristina Mestrado. Na Trilha Juvenil da Mídia Impressa. Dissertação de Mestrado. Programa de Pós-Graduação em Comunicação Social UNIVERSIDADE METODISTAA DE SÃO PAULO, São Paulo, 1999.

GUMES, Nadja Vladi Cardoso. RG_Jovem Identidades, Culturas Juvenis, Meios de Comunicação e Estilos de Vida: uma análise do caderno Folhateen da Folha de São Paulo. Dissertação de Mestrado. Programa de PósGraduação Comunicação e Cultura Contemporânea. Universidade Federal da Bahia. Salvador, 2004.
HALL, Stuart. A centralidade da cultura: notas sobre as revoluções culturais do nosso tempo. NECCSO.site: www.ufrgs.br/neccso. acesso em 23/11/2004.

HALL, Stuart. A identidade cultural na pósmodernidade. 11. ed. Rio de Janeiro : DP\&A, 2006

IULIANELLI, Jorge Atílio Silva. Juventude: Construindo processos - o protagonismo juvenil. In: FRAGA, César Pontes; Iulianelli, Jorge Atílio Silva (Orgs.). Jovens em tempo real. Belo Horizonte: DP\&A, 2003, p.54-75.

JORNAL MUNDO JOVEM, Porto Alegre: EDIPUCRS, 2009-2010.

LINK, Rosane Speggiorin. Hora do recreio!: processos de pertencimentos identitários juvenis nos tempos e espaços escolares. Dissertação de Mestrado. Programa de Pós-Graduação em Educação. Universidade Federal do Rio Grande do Sul, 2009.

MAFFESOLI, Michel. O tempo das tribos: o declínio do individualismo nas sociedade de massa. Trad. Maria de Lourdes Menezes. 4ed. Rio de Janeiro: Forense Universitária, 2010.

MANSKE, George Saliba. Um currículo para a produção de lideranças juvenis na Associação Cristã de Moços de Porto Alegre. Dissertação de Mestrado. Programa de Pós-Graduação em Educação. Universidade Federal do Rio Grande do Sul, 2006.

MARQUES, Cíntia Bueno. Pedagogia do Kzuka:Um estudo sobre a produção de identidades jovens na mídia. Dissertação (mestrado) - Universidade Luterana do Brasil.Programa de Pós-Graduação em Educação, Canoas, 2007.

MELlO, Luciana Maria Hoff de. Campanhas publicitárias 'vendendo saúde': discurso 'científico' e consumo construindo modelos de visa saudável. Dissertação de Mestrado. Programa de Pós-Graduação em Educação. Universidade Federal do Rio Grande do Sul, 2009.

NASCIMENTO, RENATO SOUZA DO. Cultura lúdica da juventude brasileira: rebeldia $\mathrm{e}$ consumo nas páginas da Veja e da Folha de São Paulo nas décadas de 1970 e 1980. Dissertação de Mestrado. Programa de Pós-Graduação em 
Ciências da Comunicação. Universidade de São Paulo. São Paulo, 2008

NELSON, Cary; TREICHLER, Paula A.; GROSSBERG, Lawrence. Estudos culturais: uma introdução. In: SILVA, Tomaz Tadeu. (org.). Alienígenas na sala de aula: uma introdução aos estudos culturais em educação. Petropólis: Vozes, 2009, p. 7-38.

NEUMAN, Laurício. Educação e Comunicação Alternativa. Dissertação de Mestrado. Programa de Pós-Graduação em Educação. Pontifícia Universidade Católica do Rio Grande do Sul (PUCRS), Porto Alegre, 1989.

OLIVEIRA, Carolina dos Santos. Adolescentes negras no discurso da Revista Atrevida. Dissertação de Mestrado. Programa de PósGraduação em Educação. Universidade Federal de Minas Gerais, 2009.

PEDROSA, Jasson Matias. Violência, mídia e juventude: análise sobre o discurso adotado pelo jornalismo impresso sobre a realidade violenta de jovens da periferia da cidade de Natal. Dissertação de Mestrado. Programa de Pós-Graduação em Ciências Sociais. Universidade Federal do Rio Grande do Norte, Natal, 2008.

PEREIRA, Angélica Silvana. Somos expressão, não subversão! : a gurizada punk em Porto Alegre. Dissertação de Mestrado. Programa de Pós-Graduação em Educação. Universidade Federal do Rio Grande do Sul, 2006.

ROSSI, Rossana Cassanta. Patrolando juventudes: o caderno Patrola ensinando jovens a consumir. Dissertação de Mestrado. Programa de Pós-Graduação em Educação. Universidade Federal do Rio Grande do Sul, 2007.

SANTOS, Lisiane Gazola. Sons das tribos: compondo identidades juvenis em uma escola urbana de Porto Alegre. Dissertação de Mestrado. Programa de Pós-Graduação em Educação. Universidade Federal do Rio Grande do Sul, 2006.

SCHMIDT, Saraí Patrícia. Ter atitude: escolha s da juventude líquida - um estudo sobre mídia, educação e cultura jovem global. Dissertação de Mestrado. Programa de Pós-Graduação Universidade Federal do Rio Grande do Sul. Porto Alegre, 2006.
SILVA, Eloenes. A gente chega e se apropria do espaço! Graffiti e pichações demarcando espaços urbanos em Porto Alegre. Dissertação de Mestrado. Programa de Pós-Graduação em Educação. Universidade Federal do Rio Grande do Sul. Porto Alegre, 2010.

SILVA, Tomaz Tadeu da. A produção social da identidade e da diferença. In:

Identidade e diferença: a perspectiva dos estudos culturais. 9 ed. Petrópolis: Vozes, 2009, p.73-102.

Documentos de Identidade - uma introdução às teorias de currículo. $2^{\mathrm{a}}$ ed. $11^{\mathrm{o}}$ reimpressão. - Belo Horizonte: Autêntica, 2007.

SILVA, Thais Coelho da. Juventude transviada: identidades marcadas invadem a rua. Dissertação de Mestrado. Programa de PósGraduação em Educação. Universidade Federal do Rio Grande do Sul, 2008.

SILVA DOS SANTOS, Lidia Noemia Silva dos Santos. Sonhos dourados: juventudes na imprensa fortalezense da década de 50. Dissertação de Mestrado. Programa de PósGraduação em História. Universidade Federal do Ceará, Ceará 2005.

SEVERO, Rita Cristine Basso Soares. As gurias normais do curso normal do Instituto de Educação de Porto Alegre. Dissertação de Mestrado. Programa de Pós-Graduação em Educação. Universidade Federal do Rio Grande do Sul, 2008.

SOUZA, Rui Antônio de. Idéias de educação na comunicação do jornal mundo jovem: 1963 a 2005. Dissertação de Mestrado. Programa de PósGraduação em Comunicação Social. Pontifícia Universidade Católica do Rio Grande do Sul. Porto Alegre, 2008.

STEINBERG, Shirley R. Kindercultura: a construção da infância pelas grandes corporações. In: SILVA, Luiz Heron da. Identidade Social e Construção do Conhecimento. Porto Alegre: Ed. Secretaria Municipal de Educação de Porto Alegre - Prefeitura Municipal de Porto Alegre, 1997, p.98-145.

XAVIER, Maria Luisa Merino de Freitas. Os incluídos na escola: o disciplinamento nos processos emancipatórios. Tese (doutorado) Universidade Federal do Rio Grande do Sul. 
Faculdade de Educação. Programa de PósGraduação em Educação, Porto Alegre, 2003.

WOORDWARD, Kathryn. Identidade e Diferença: uma introdução teórica e conceitual.
In:. Silva, Tomaz Tadeu da. Identidade e diferença : a perspectiva dos estudos culturais. 9 ed. Petrópolis: Vozes, 2009, p.7-72. 


\section{Notas}

1 O Seminário Maior de Viamão é um local de preparação cristã para a vida no sacerdócio. Foi criado em 1955 e é vinculado à Pontifícia Universidade Católica do Rio Grande do Sul através de alguns cursos de graduação acadêmica e formações religiosas.

2 Equipe vocacional é constituída por pessoas que orientam e prestam serviços pedagógicos aos Seminários na preparação de futuros padres.

3 Esta informação foi retirada do site www.pucrs.mundojovem.br

4 Igreja Católica situada na Avenida Cristóvão Colombo, n 1629 , Bairro Floresta. Porto Alegre, Rio Grande do sul.

5 Em determinadas edições se observou a presença dessa nova seção.

6 Campanha de uma emissora de televisão do Rio Grande do Sul que visa debater o cenário da educação gaúcha apresentando, para tanto, especialistas de diversas áreas comentando sobre a educação.

7 Ver mais sobre processos de resistências em Foucault (2010).

\section{Sobre as autoras:}

Lisandra Veiga dos Santos: Mestra em Educação e Estudos Culturais (PPGEDU/UFRGS) e Professora Anos Iniciais da Rede Marista no Rio Grande do Sul.

Elisabete Maria Garbin: Doutora em Educação e Estudos Culturais (PPGEDU/UFRGS) e Professora na Faculdade de Educação/UFRGS). 